\title{
Selective Killing of Murine Leukemic Cells by Adenosine Triphosphate (ATP): A Study of the Value of Autologous Bone Marrow Transplantation
}

\author{
Yoshihiro Hatta, Shin Aizawa*, Akira Horikoshi, Masumi Baba and Takashi Horie
}

\begin{abstract}
To assess the value of adenosine triphosphate (ATP) for ex vivo purging of leukemic cells in autologous bone marrow transplantation, its biological effects on the murine leukemic cell lines (WEHI3B and L1210) and normal murine bone marrow hemopoietic stem cells (CFU-C and CFUS) were studied. After treatment with $4 \mathrm{mM}$ of ATP for $6 \mathrm{~h}$, the number of viable WEHI3B cells decreased to less than $0.1 \%$ of that of the control. Furthermore, ${ }^{3} \mathrm{H}$-thymidine incorporations were also completely inhibited in both WEHI3B cells and L1210 cells. These phenomena were related to the concentration and exposure period of ATP. Treatment of bone marrow mononuclear cells with ATP under the same condition reduced the number of CFU-C, day 9 CFU-S and day 12 CFU$S$ to only $58.5 \pm 8.7 \%, 92.6 \pm 8.2 \%$ and $83.5 \pm 28.5 \%$, respectively, with no change in the number of marrow nucleated cells. Although the effect of ATP is not entirely specific to leukemic cells, these findings provide evidence that ATP is useful for purging residual tumor cells in autologous bone marrow transplantation.
\end{abstract}

(Internal Medicine 32: 768-772, 1993)

Key words: WEHI3B, L1210, purging, hemopoietic stem cell, cell membrane, permeability

\section{Introduction}

Allogeneic bone marrow transplantation (Allo-BMT) has been used for treatment in a large number of patients with leukemia, although the bone marrow should be obtained from an HLA-identical donor. Even when allo-BMT is performed, acute or chronic graft-versus-host disease (GVHD) frequently occurs resulting in a serious patient condition. Autologous bone marrow transplantation (Auto-BMT) is useful in avoiding these problems, but another major problem has appeared: how the residual tumor cells in bone marrow are detected and purged.

Recently, Di Virgilio and colleagues reported that extracellular adenosine triphosphate (ATP) has a cytotoxic effect for lymphoma cells by inducing depolarization and by increasing the permeability of the cell membrane (1). A similar cytotoxic effect of exogenous ATP on the 9-L glioma cell line (2), EL-4 tumor cell line (3), P-815 mastocytoma cell line (3), YAC-1 lymphoma cell line (1), and MBL-2 lymphoma cell line (1) has been also revealed. Although the effect of extracellular ATP on normal hemopoietic stem cells must be examined before clinical application, this has not been reported previously. In the present report, we studied the biological effects of ATP on the murine myelomonocytic leukemic cells (WEHI3B), the murine lymphocytic leukemic cells (L1210) and hemopoietic stem cells (CFU-C and CFU-S). The selective killing of WEHI3B cells and L1210 cells but not CFU-S by treatment with ATP suggests the availability of ATP for purging the residual leukemic cells in auto-BMT.

\section{Materials and Methods}

\section{Cells}

WEHI3B and L1210 cells were maintained in alpha-modification of minimum essential medium (alpha-MEM, Flow Lab. Inc., McLean, Va., U.S.A.) supplemented with $10 \%$ fetal calf serum (FCS) at $37^{\circ} \mathrm{C}$ in $5 \% \mathrm{CO}_{2}$ in air.

Normal male 11-week-old BDF1 mice were killed by cervical dislocation. Their femurs and tibias were aseptically isolated and marrow cells were gently flushed out by repeated injection of alpha-MEM through a syringe with a 23-gauge needle. Bone marrow mononuclear cells (BMMNC) were then isolated by Ficoll-Paque density centrifugation, and used as a

From the First Department of Internal Medicine, Nihon University School of Medicine, Tokyo and *the First Department of Internal Medicine, Tokyo Medical College, Tokyo

Received for publication March 10, 1993; Accepted for publication October 29, 1993

Reprint requests should be addressed to Dr. Yoshihiro Hatta, the First Department of Internal Medicine, Nihon University School of Medicine, 30-1, Oyaguchi Kamimachi, Itabashi-ku, Tokyo 173 
source of hemopoietic stem cells.

Treatment procedure with ATP

Adenosine triphosphate (ATP, Sigma Chemical Co., St. Louis, Mo., U.S.A.) was dissolved with alpha-MEM, adjusted to $\mathrm{pH} 7.40$ and stored at $-70^{\circ} \mathrm{C}$ until use. Leukemic cells or BMMNC in alpha-MEM supplemented with $10 \%$ FCS at $1 \times 10^{6} / \mathrm{ml}$ were incubated with various concentrations of ATP at $37^{\circ} \mathrm{C}$ in $5 \% \mathrm{CO}_{2}$ in air. Following $30 \mathrm{~min}, 3$ hours and 6 hours of incubation, the number of viable cells was counted by trypan blue dye exclusion. After cells were washed twice with alphaMEM, clonogenic assay for hemopoietic stem cells (CFU-C and $\mathrm{CFU}-\mathrm{S}$ ), and a ${ }^{3} \mathrm{H}$-thymidine incorporation assay for leukemic cells were examined.

\section{Clonogenic assay for $C F U-C$ and $C F U-S$}

ATP-treated BMMNC were washed twice and resuspended in alpha-MEM. Then cells were incubated in a semisolid culture medium containing $0.3 \%$ agar, $20 \%$ FCS and $10 \%$ L-cellconditioned medium as a colony stimulating factor in alphaMEM, for 7 days at $37^{\circ} \mathrm{C}$ in $5 \% \mathrm{CO}_{2}$ in air. The colonies containing more than 40 cells were counted as CFU-C.

The number of CFU-S were measured according to the method of Till and McCulloch (4). BMMNC treated with or without ATP were resuspended with alpha-MEM and were injected via the tail vein into 11 -week-old BDF1 male mice that had been irradiated with 9 Gy. Nine and 12 days later, the spleens were removed and fixed in Bouin's solution, then colonies were counted at day 9 CFU-S and day 12 CFU-S.

\section{${ }^{3} H$-thymidine incorporation study}

The ${ }^{3} \mathrm{H}$-thymidine incorporation was examined for the estimation of biological activity of leukemic cells. ATP-treated leukemic cells were washed twice and resuspended in alphaMEM supplemented with $10 \%$ FCS. A $0.2 \mathrm{ml}$ portion of this cell suspension was plated in 96-well flat-bottomed culture trays (Costar, Cambridge, Mass., U.S.A.), and incubated for 6 hours at $37^{\circ} \mathrm{C}$ in $5 \% \mathrm{CO}_{2}$ in air in the presence of $0.5 \mu \mathrm{Ci}$ of ${ }^{3} \mathrm{H}$ thymidine (Amersham, Amersham, Buckinghamshire, U.K.). Then cells were harvested and their counted radioactivity using a liquid scintillation counter.

\section{Detection of ATPase in the cell membrane}

ATPase in the cell membrane was detected by using the Wachstein-Meisel staining method (5). The activity of ATPase detected by this method, which is $\mathrm{Ca}^{2+} \mathrm{Mg}^{2+}$ ATPase activity, was observed as dark brown deposits of $\mathrm{Pb}_{3} \mathrm{P}_{2}$ by microscopy.

\section{Statistical analysis}

All experiments were performed in triplicate or quadruplicate and repeated for three times. Values were represented as mean $\pm S D$. The statistical significance of difference was calculated using Wilcoxon's test.

\section{Results}

Cytotoxic effects of ATP on leukemic cells and hemopoietic cells

The leukemic cells (WEHI3B and L1210) and BMMNC were incubated with various concentrations of ATP and the number of viable cells were counted after $30 \mathrm{~min}, 3$ hours and 6 hours. As shown in Fig. 1, the number of viable cells of WEHI3B was decreased in relation to the ATP concentration and incubation period. When WEHI3B was treated with $4 \mathrm{mM}$ of ATP for 6 hours, the number of viable cells was decreased to less than $0.1 \%$ of the sham-treated control. The number of viable L1210 cells was also decreased with ATP in a time and dose dependent manner (Data not shown).

On the other hand, the number of viable BMMNC was not changed by the introduction of any concentration of ATP (Fig. 2).

\section{Effects of ATP on ${ }^{3} \mathrm{H}$-thymidine incorporation of leukemic cells}

${ }^{3} \mathrm{H}$-thymidine incorporation on WEHI3B was examined after treatment with various concentrations of ATP (Fig. 3). Percentage of ${ }^{3} \mathrm{H}$-thymidine incorporation of WEHI3B was decreased according to the concentration and exposure period of ATP. After 6 hours of treatment with $4 \mathrm{mM}$ of ATP, ${ }^{3} \mathrm{H}-$ thymidine incorporation was markedly inhibited when com-

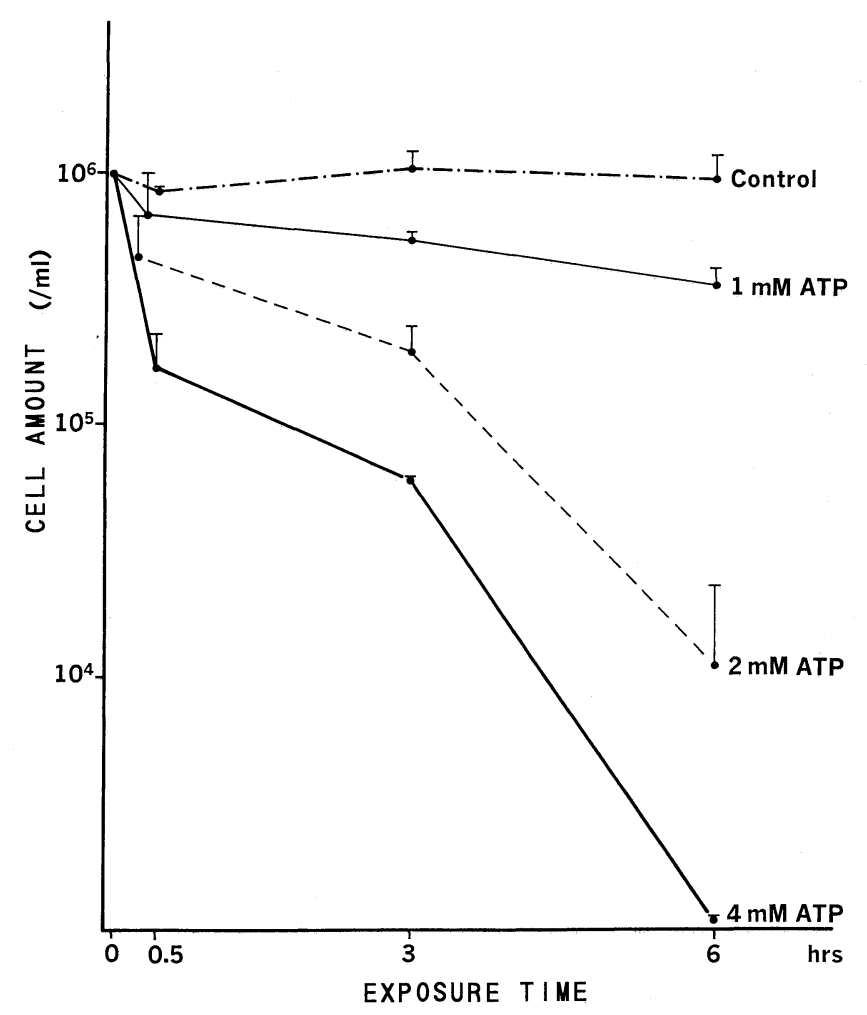

Fig. 1. The decreased number of WEHI3B after treatment with ATP. WEHI3B cells were exposed to adenosine triphosphate (ATP) with $1 \mathrm{mM}(-)$, $2 \mathrm{mM}(---), 4 \mathrm{mM}(-)$, and control without ATP (-- $)$. Initial cell amount was $1 \times 10^{6} / \mathrm{ml}$. Each point and bar represents the mean and SD. 


\section{HatTA et al}

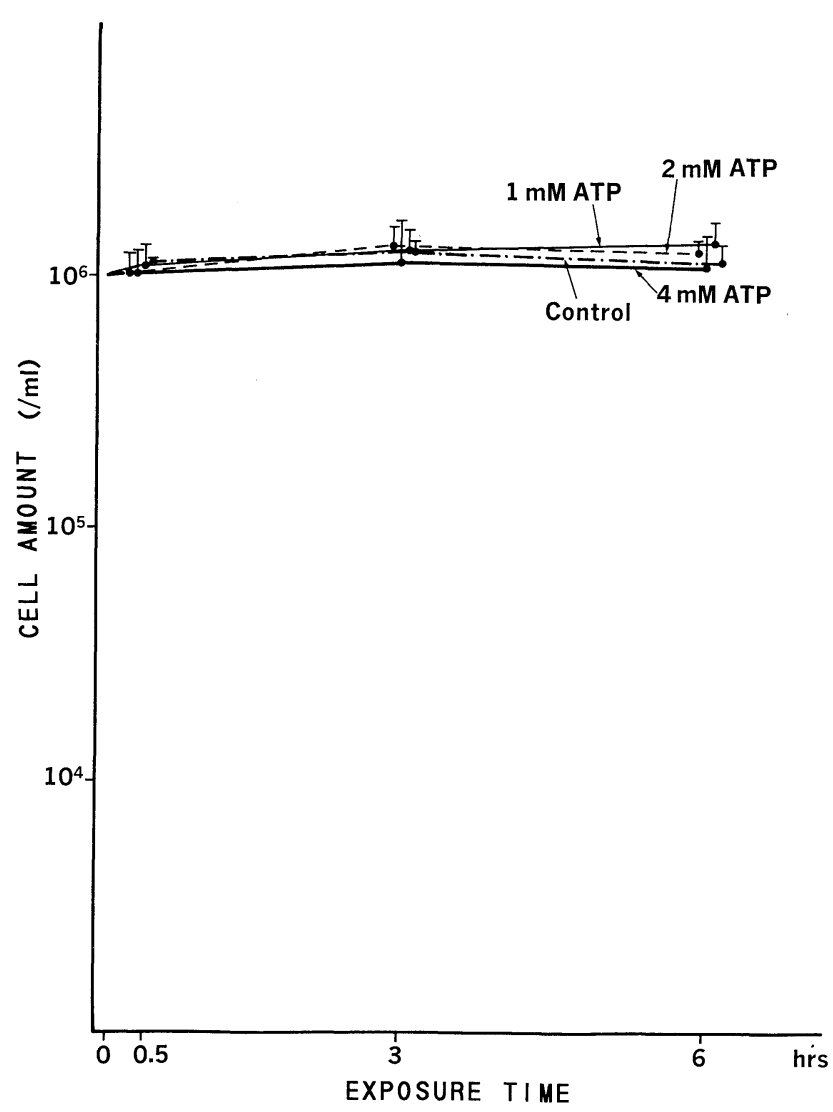

Fig. 2. The change in normal bone marrow cell amount after treatment with ATP. Normal BDF1 male mouse bone marrow cells were exposed to adenosine triphosphate (ATP) with $1 \mathrm{mM}(-), 2 \mathrm{mM}(----), 4 \mathrm{mM}(-)$, and control without ATP (-- $)$. Initial cell amount was $1 \times 10^{6} / \mathrm{ml}$. Each point and bar represents the mean and SD.

pared with the sham-treated control. Furthermore, ${ }^{3} \mathrm{H}$-thymidine incorporation of L1210 cells was almost completely inhibited compared with the untreated control after incubation with 4 mM ATP for 3 hours or 6 hours (Fig. 3).

\section{Survival of hemopoietic stem cells (CFU-C and CFU-S) after treatment with ATP}

The number of colonies treated without ATP for $30 \mathrm{~min}, 3$ hours, 6 hours was $158 \pm 10.4,180.5 \pm 6.8,178.3 \pm 23.9$ per $1 \times 10^{5}$ plated cells, respectively. Figure 4 shows the influence of ATP on CFU-C. Even with $4 \mathrm{mM}$ ATP, the percent of CFU-C was $58.5 \pm 8.7 \%$ of control after 6 hours of incubation.

As shown in Table 1, the number of CFU-S remained at $92.6 \%$ in day 9 CFU-S and $83.5 \%$ in day 12 CFU-S compared with the sham-treated control in spite of $4 \mathrm{mM}$ ATP treatment for 6 hours. But these decreases were not significant.

\section{Detection of ATPase activity in the cell membrane}

Figure 5 shows the pictures of WEHI3B cells, and BMMNC stained by the Wachstein-Meisel staining method. Dark brown deposits represent the presence of ATPase. ATPase was detected in the cytoplasm and cell surface of WEHI3B cells,

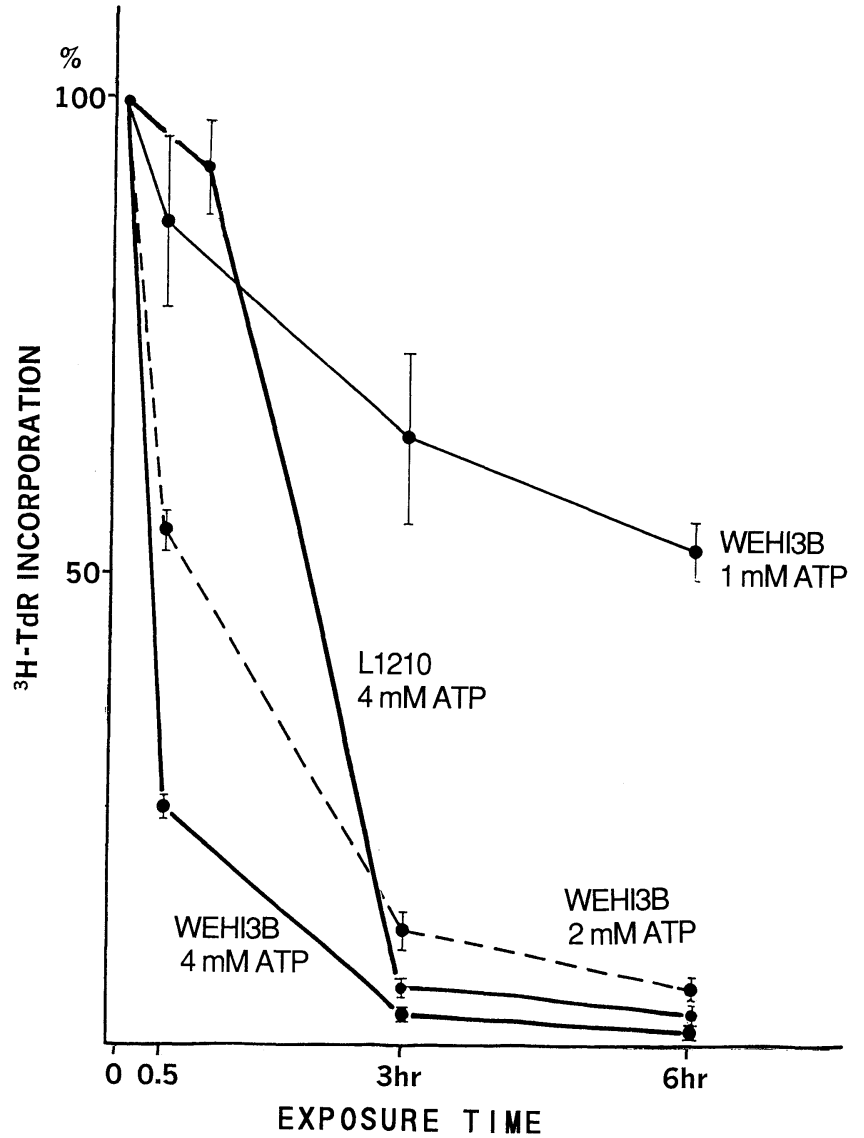

Fig. 3. Effect of ATP on ${ }^{3} \mathrm{H}$-thymidine incorporation of leukemic cells. WEHI3B cells were incubated with $0,1,2$, and $4 \mathrm{mM}$ adenosine triphosphate (ATP) for $30 \mathrm{~min}, 3$ hours and 6 hours. Then cells were incubated with $0.5 \mu \mathrm{Ci}$ of ${ }^{3} \mathrm{H}$-thymidine for 6 hours, and their ${ }^{3} \mathrm{H}$-thymidine incorporations were counted using a liquid scintillation counter. Exposure to ATP exhibited dose and time dependent suppression of ${ }^{3} \mathrm{H}$-thymidine incorporation. The ${ }^{3} \mathrm{H}$ thymidine incorporation of L1210 cells after $4 \mathrm{mM}$ ATP treatment was also decreased in a time dependent manner. $100 \%$ indicates the ${ }^{3} \mathrm{H}$-thymidine incorporation of cells incubated with ATP-free medium. Each point and bar represents the mean and SD.

showing as a granular pattern (Fig. 5a). On the other hand, as shown in Fig. 5b, ATPase was not detected either in the cytoplasm or cell membrane of BMMNC.

\section{Discussion}

Recently, a technique of autologous bone marrow transplantation (Auto-BMT) has been developed, and applied for various hematological disorders. When compared with allogeneic bone marrow transplantation (Allo-BMT), this technique has at least two major advantages: 1) an HLA identical donor is not necessary, and 2) Auto-BMT can avoid the risk of acute or chronic GVHD. However, in the case of leukemia, residual leukemic cells in transplanted bone marrow sometimes cause 'relapse.' Although purging for residual leukemic cells by using monoclonal antibodies has been reported (6), monoclonal 


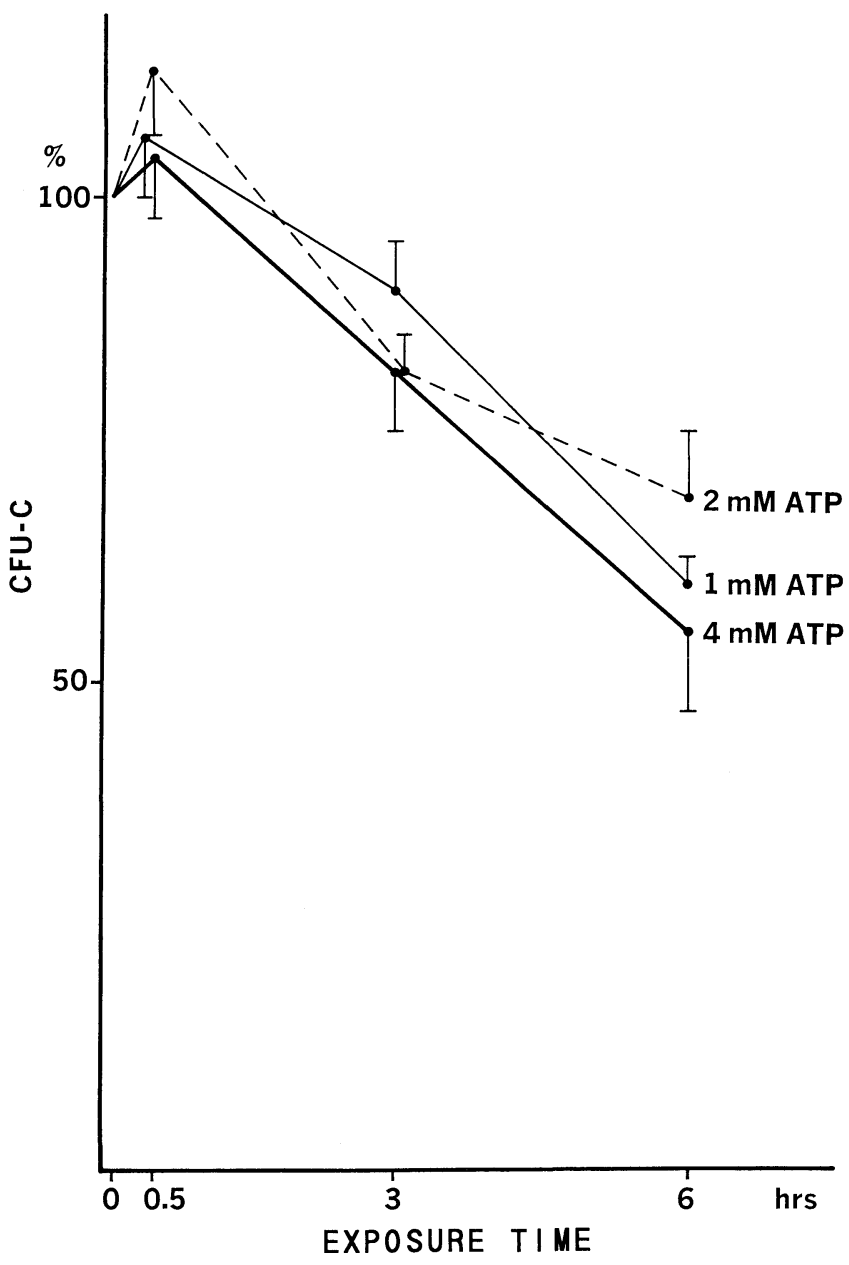

Fig. 4. Effect of ATP on CFU-C. After normal murine bone marrow cells were incubated with $0,1,2$, and $4 \mathrm{mM}$ adenosine triphosphate (ATP) for $30 \mathrm{~min}$, 3 hours and 6 hours, their CFU-C were assayed in semisolid agar cultures. CFU-C remained at $58.5 \pm 8.7 \%$ in number after 6 hours of treatment with $4 \mathrm{mM}$ ATP compared with the ATP-free control group. Each point and bar represents the mean and SD.

Table 1. Effect of ATP on CFU-S

\begin{tabular}{cccc}
\hline $\begin{array}{c}\text { ATP } \\
\text { concentrations (mM) }\end{array}$ & $\begin{array}{c}\text { Incubation } \\
\text { period (h) }\end{array}$ & $\begin{array}{c}\text { Day 9 CFU-S } \\
\text { colonies (\%) }\end{array}$ & $\begin{array}{c}\text { Day 12 CFU-S } \\
\text { colonies (\%) }\end{array}$ \\
\hline 0 & 0 & $20.9 \pm 2.9(100.0)$ & $18.8 \pm 4.0(100.0)$ \\
0 & 3 & $22.3 \pm 3.4(107.0)$ & ND \\
0 & 6 & $21.3 \pm 2.1(102.2)$ & $17.8 \pm 2.6(94.6)$ \\
4 & 3 & $22.0 \pm 3.4(105.6)$ & ND \\
4 & 6 & $19.3 \pm 1.7(92.6)$ & $15.7 \pm 5.4(83.5)$ \\
\hline
\end{tabular}

Each value is the mean \pm SD. ND: not done. The decrease of CFU-S is not significant.

antibodies recognizing leukemic cells specifically, especially in the case of nonlymphocytic leukemia, must be produced.

In this paper, the cytotoxic effects of ATP against the murine myelomonocytic leukemic cells (WEHI3B), the murine lymphocytic leukemic cells (L1210) and hemopoietic stem
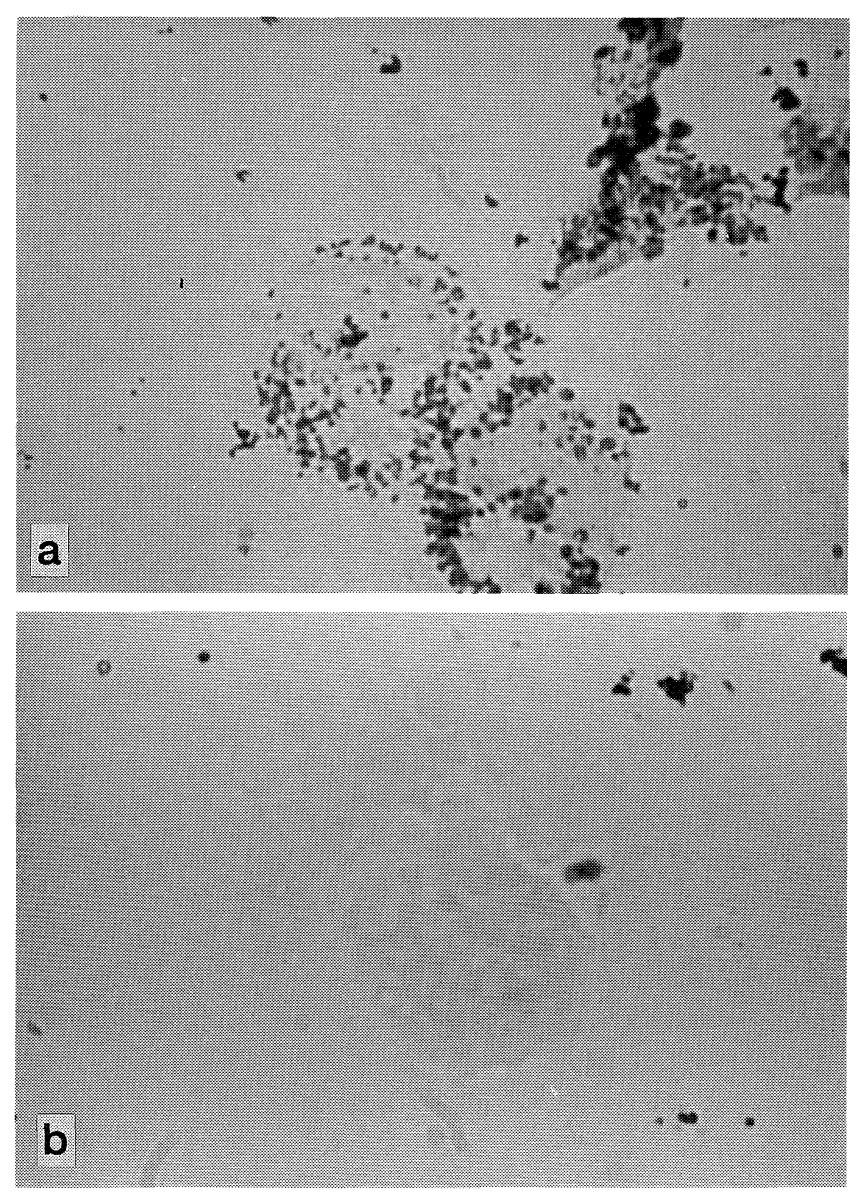

Fig. 5. Histochemical demonstrations of $\mathrm{Ca}^{2+} \mathrm{Mg}^{2+} \mathrm{ATPase}$ activities in murine leukemic cells and normal bone marrow mononuclear cells (WachsteinMeisel Method). $\mathrm{Ca}^{2+} \mathrm{Mg}^{2+}$ ATPase activities were recognized as fine granular dark brown deposits on the cell membrane of WEHI3B cells $(5 \mathrm{a}, \times 400)$. ATPase was not detected on normal murine mononuclear cells $(5 b, \times 400)$.

cells were studied. The reduction of the cell number and ${ }^{3} \mathrm{H}-$ thymidine incorporation were observed in both WEHI3B and L1210 after ATP treatment in correlation with the concentration and exposure period to ATP. Both leukemic cells were severely damaged by treatment with $4 \mathrm{mM}$ ATP for 6 hours (Figs. 1 and 3).

Less cytotoxic effects of ATP against hemopoietic stem cells (CFU-C and CFU-S) were observed. The number of CFUC, day 9 CFU-S and day 12 CFU-S remained to be $58.5 \%$, $92.6 \%$ and $83.5 \%$ of sham-treated control, respectively, after treatment with $4 \mathrm{mM}$ of ATP for 6 hours, while more than 99.9\% of WEHI3B cells were killed. The finding that CFU-S showed resistance against ATP is very important, regarding the phenomena of reconstitution of hemopoiesis after bone marrow transplantation. Alkyl-lysophospholipid (ALP, ET-18$\mathrm{OCH} 3$ ) is known to be a purging agent, however, it has some cytotoxic effect on CFU-S (7). Thus, a small cytotoxic effect of ATP against hemopoietic stem cells suggests the utility of ATP for clinical use in Auto-BMT.

Although, the mechanism of the toxicity of ATP on leukemic 
cells is still unclear, ecto-ATPase, an ecto-enzyme, is considered to be involved in part. Ecto-ATPase was first detected on the surface membrane of nucleated erythrocytes by Engelhardt (8) and the presence of similar enzyme activity was found in leukocytes $(9,10)$, hepatocytes (11) and astroglia (12). Furthermore, this enzyme activity was demonstrated to be high on the surface membrane of the Ehrlich tumor cells (13), neuroblastoma cell (14), HeLa cell (12) and other malignant tumor cells (1517). We also detected ATPase on WEHI3B cell membrane by using the Wachstein-Meisel staining method.

Ecto-ATPase has been suggested to play a role in the depolarization of the cell membrane. Excess of extracellular ATP can activate ATPase localized on the tumor cell membrane. The activated ATPase may change the membrane permeability, which pulls water into the cells, resulting in hydropic degeneration of cells and also change in ionic distribution across the cell membrane. In fact, an increase in intracellular $\mathrm{Na}^{+}$and $\mathrm{Ca}^{2+}$ and decrease in intracellular $\mathrm{K}^{+}$concentration were reported after extracellular application of ATP to the Ehrlich tumor cell by Hempling and colleagues (18) and to the 9-L glioma cell by Miyagi (2). Recently, Wiley and Duybak reported that the cells obtained from patients with chronic lymphocytic leukemia showed the uptake of cations from treatment with ATP (19). Di Virgilio and colleagues also reported that treatment of extracellular ATP induced depolarization and increased permeability of the lymphoma cell membrane (1). However, he also found that $\mathrm{ATP}^{4}$ was more effective than $\mathrm{ATP}^{0}$ for plasma membrane permeabilization. Steinberg and Silverstein revealed that permeability of the cell membrane correlated well with $\mathrm{ATP}^{4-}$ and poorly with $\mathrm{MgATP}^{2-}$ which was a substrate for all known ATPase (20). These observations suggest that the $\mathrm{ATP}^{4-}$ receptor mainly participates in ATP-mediated cell death.

We examined, the effects of ATP on hemopoietic stem cells, which have not been previously reported, using the clonogenic assay. ATP treatment induced irreversible damage to the leukemic cells without injuring normal hemopoietic stem cells. Although further studies are required before medical application, all of the present findings suggest that ATP treatment is useful for purging residual leukemic cells in auto-BMT.

\section{References}

1) Di Virgilio F, Bronte V, Collavo D, Zanovello P. Responses of mouse lymphocytes to extracellular adenosine 5'-triphosphate (ATP). J Immunol 143: 1955, 1989.

2) Miyagi A. Cell membrane mechanism for regulation of ion changes and uptake of antitumor metal complex in the malignant tumor cells. J Nihon Univ Med Ass 46: 231, 1987 (abstract in English).

3) Filippini A, Taffs RE, Agui T, Sitkovsky MV. Ecto-ATPase activity in cytolytic T-lymphocytes. J Bio Chem 265: 334, 1990.

4) Till JE, McCulloch EA. A direct measurement of the radiation sensitivity of normal mouse bone marrow cells. Radiation Res 14: 213, 1961.

5) Wachstein M, Meisel E. Histochemistry of hepatic phosphatases at a physiologic pH. Am J Clin Path 27: 13, 1957.

6) Siena S, Villa S, Bregni M, Bonnadonna G, Gianni AM. Amantadine potentiates $\mathrm{T}$ lymphocyte killing by an anti-pan-T cell (CD5) ricin Achain immunotoxin. Blood 69: 345, 1987.

7) Glasser L, Somberg LB, Vogler WR. Purging murine leukemic marrow with alkyl-lysophospholipids. Blood 64: 1288, 1984.

8) Engelhardt WA. Enzymes as structural elements of physiological mechanisms. Proc Int Symp Enz Chem (Tokyo and Kyoto) 2: 163, 1957.

9) DePierre JW, Karnovsky ML. Ecto-enzyme of granulocytes. Science 183: 1096, 1974.

10) Chambers DA, Salzman EW, Neri LL. Characterization of "EctoATPase" of human blood platelets. Arch Biochem Biophys 119: 173, 1967.

11) Karasaki S, Okigaki T. Surface membrane nucleoside triphosphate activity and tumorigenicity of cultured liver epithelial cells. Cancer Res 36: 4491, 1976.

12) Ågren G, Ponten J, Ronquist G. Formation of extracellular adenosine triphosphate by normal and neoplastic human cells in culture. J Cell Physiol 77: 331, 1971.

13) Ronquist $\mathrm{G}, \AA ̊ \AA g$ gren $\mathrm{GK}$. $\mathrm{AMg}^{2+}$ and $\mathrm{Ca}^{2+}$ stimulated adenosine triphosphate at the outer surface of Ehrlich ascites tumor cells. Cancer Res 35: 1402, 1975.

14) Stefanovic V, Treska JC, Ebel A, Mandel P. Nucleoside triphosphate activity at the external surface of neuroblastoma cells. Brain Res 81: 427, 1974.

15) Banerjee RK. Ecto-ATPase. Mole Cell Biochem 37: 91, 1981.

16) Stefanovic V, Ledig M, Mandel P. Divalent cation-activated ectonucleotide triphosphate activity of nervous system cells in tissue culture. J Neurochem 27: 799, 1976.

17) Ågren G, Ponten J, Ronquist G, Westermark B. Demonstration of an ATPase at the cell surface of intact normal and neoplastic human cells in culture. J Cell Physiol 78: 171, 1971.

18) Hempling HG, Stewart CC, Garic G. The effect of exogenous ATP on the electrolyte content of TA3 ascites tumor cells. J Cell Physiol 73: 133, 1969.

19) Wiley JS, Duybak GR. Extracellular adenosine triphosphate increases cation permeability of chronic lymphocytic leukemic lymphocytes. Blood 73: 1316, 1989.

20) Steinberg TH, Silverstein SC. Extracellular ATP promotes cation fluxes in the J774 mouse macrophage cell line. J Biol Chem 262: 3118, 1987. 